\title{
RAA System and Exercise Relationship
}

\author{
Süleyman PATLAR ${ }^{1}$, Sadettin ÜNSAL ${ }^{2}$ \\ ${ }^{1}$ Faculty of Sport Science, Selcuk University, Konya, Turkey. \\ 2Department of Biology, Faculty of Sciences, Selcuk University, Konya, Turkey.
}

Address Correspondence to S, Patlar e-mail: spatlar@selcuk.edu.tr

\begin{abstract}
In this review, it is aimed to discuss the possible interactions between renin-angiotensin-aldosterone system and exercise for health and performance and to present new literature on this subject. From this point of view, an analysis of the experimental and clinical studies on this subject has been made. Physical exercise leads to a number of changes in the plasma levels of renin, angiotensin, and aldosterone, which represent the adaptation of the human body to a new biological environment. Significant $(\mathrm{P}<0.05)$ increases occur in the levels of plasma renin, angiotensin and aldosterone especially in submaximal and maximal exercise intensity. Hormone levels return to normal with the end of the exercise. Factors such as age and gender, menstrual cycle, salt intake, posture, thermal tension, elevation, training, type of exercise have a major impact on the response of the RAA system to exercise. A relationship between physical activity and permanent endocrine changes could not be demonstrated.
\end{abstract}

Key Words: Renin-angiotensin-aldosterone system

\section{INTRODUCTION}

The RAA system is an endocrine system that plays an important role in many hemostatic events in the body. In particular, fluid-electrolyte balance, blood volume, and arterial blood pressure regulation and maintains the basic task of maintaining the physiological level $(12,17,24,39)$

Research on this topic shows that the RAA system is immediately activated, especially with the loss of sodium and water in the body during exercise, and an increase in renin-angiotensinaldosterone levels occurs. Some authors observed that renin and aldosterone levels increased during and after exercise, returned to pre-exercise levels during a rest period of 6-12 hours, and sodium and water excretion remained suppressed for up to 48 hours $(10,13)$. Staessen et al. (50) stated that plasma levels of angiotensin and aldosterone increased at similar rates in mild to moderate exercise $(30 \%$ and $60 \%$ ) or angiotensin II increased significantly more than PRA and aldosterone in maximal (above anaerobic threshold) exercises. However, it is hard to interpret hormonal changes because of the variety of environmental changes, the exercise protocol, and the characteristics of different subjects. Therefore, new research is needed.

The aim of this review is to discuss the possible interactions between RAA system and exercise for health and performance and to present new literature on this topic.

\section{Renin}

Renin is a proteolytic enzyme with glycoprotein structure and molecular weight of approximately 36000 daltons. However, some publications have reported that it is an (atypical) hormone. $(15,61)$.

\subsection{Oscillation and Regulation}

Juxtaglomerular cells in the kidney are the most important formations that release renin and are the major source of renin in plasma. However, in some tissues other than the kidney (salivary glands, vascular beds) renin is produced and released. The decrease in arterial pressure (hypotension), decreases tension (tonus) in renal arterioles and narrowing of renal arteries as a result of the decrease in pressure within the lumen and excessive decrease in circulating blood amount (hypovolemia) increases renin release $(23,41)$.

Catecholamines released by stimulation of the central nervous system and increased sympathetic activity greatly increase the release of renin in juxtaglomerular cells via sAMP and ๑-adrenergic receptors.

There is an inverse relationship between the concentration of $\mathrm{Na}$ and $\mathrm{Cl}$ passing through these 
cells and the release of renin. Macular densa contains chemical receptors that are sensitive to sodium and chlorine ions in the filtrate. in the concentration of sodium and chlorine ions in the filtrate leads to the stimulation of the receptors in question. These stimulated receptors also increase the release of renin by affecting the adjacent juxtaglomerular cells $(18,41,61)$.

\section{Angiotensin}

\subsection{Oscillation and Regulation}

Angiotensin is a plasma glycoprotein formed in the liver with a molecular weight of 55000 daltons. The renin enzyme released from the kidneys has an enzymatic effect on this angiotensinogen in the $\alpha 2$ globulin structure in plasma. As a result of this effect, renin angiotensinogen converts to angiotensin I. Renin remains in circulation for 30 minutes and during this time angiotensin, I continue to form. Angiotensin $\mathrm{I}$ is a peptide containing 10 amino acids and has a moderate vasoconstrictive effect. Therefore, it is not sufficient to make significant changes in blood circulation alone (15).

Angiotensin I, a few seconds after its formation, loses 2 amino acids with the effect of kininase II which exists mostly in the lungs, blood and organs (adrenal shell, kidney, liver, posterior pituitary, pancreas, spleen). and an angiotensin II, an 8-amino acid peptide, occurs. Angiotensin II is the most potent vasoconstrictive hormone known and has effects outside circulation (12).

\subsection{The Effect}

Angiotensins have two major effects. They are vasoconstriction and the increase of the release of aldosterone. Furthermore, thirst increases the release of antidiuretic hormones and reduces the formation of urine by stimulation of the central nervous system and the heart

\section{Aldosterone}

Three different mineralocorticoid hormones, aldosterone, deoxycosterone (DOC) and corticosterone, are released from the zona glomerulus of the adrenal gland cortex. These hormones are called mineralocorticoids because they act on electrolytes such as sodium, potassium, and chlorine, especially in extracellular fluids. Glucocorticoids are oxygen-free corticoids at carbon atom number 11 . In a healthy person, about 50-250 $\mathrm{mg}$ of aldosterone and deoxycorticosterone are released per day. Therefore, plasma aldosterone level is very low $(0.01 \mu \mathrm{g} / 100 \mathrm{ml})$. On the other hand, aldosterone provides $95 \%$ of the mineralocorticoid activity. The remaining 5\% activity is also fulfilled by the other two mineralocorticoid hormones $(41,61)$

\subsection{The Structure}

Aldosterone is similar in structure to corticosterone. However, the carbon atom number 18 of corticosterone has been replaced by an aldehyde group instead of the methyl group. Since this aldehyde group is adjacent to the hydroxyl ($\mathrm{OH})$ group at carbon atom number 1 in space, it allows the formation of the hemiacetal form of aldosterone. For this reason, aldosterone is present in the form of aldehyde and hemiacetal and is in equilibrium.

\subsection{Oscillation and Regulation}

A very small proportion of aldosterone that passes into the blood is bound to plasma proteins. The rest is free. The amount released is very small and the total plasma aldosterone level in humans is about $0.006 \mu \mathrm{g} / \mathrm{dl}$. Aldosterone secretion is regulated by the following changes, particularly plasma potassium and angiotensin levels.

1. One of the most powerful stimulises that increase aldosterone secretion is potassium ions. Indeed, when potassium ions increase in extracellular fluids, the release of aldosterone increases. An increase in potassium ions up to $1 \mathrm{meq}$ / L in the extracellular fluid leads to a threefold increase in aldosterone release. This potent effect of potassium ions is very important.

2. One of the important stimuluses that increase aldosterone secretion is the decrease in blood volume due to various reasons. Hemorrhage, use of diuretics, ganglion blockade in the case of low salt intake and the decrease of the extracellular fluid volume in some important chronic diseases cause to the reduction in the bloodstream and arterial pressure.

3. Aldosterone secretion is not as sensitive to plasma sodium as it is at the potassium level. Therefore, the reduction of sodium ions (hyponatremia) in extracellular fluid or blood is a weak stimulus that causes aldosterone release. A decrease in plasma sodium level of up to $20 \mathrm{meq} / \mathrm{L}$ may indirectly increase aldosterone release.

4. The effect of sodium level and ACTH in the control and regulation of aldosterone release is not 
as potent as potassium ions and angiotensin, in other words, it is insignificant. Indeed, as a result of ACTH injection, aldosterone secretion initially increases for several days, but the effect then disappears. While ACTH increases the release of glucocorticoids, it also plays a role in preparing for the partial release of aldosterone if even it is for a short while(61).

\subsection{The Effect}

The most important effect of aldosterone is on renal distal tubules and collector channels. It acts on sodium, potassium and water metabolism and regulates the concentration of these substances in intercellular fluids and blood. While Aldosterone provides the absorption of sodium ions from the renal tubules, on the other hand, it increases the urine extraction of potassium ions and, to a lesser extent, hydrogen ions (18).

\section{Physiology of Renin-Angiotensin-Aldosterone System}

The RAA system is an endocrine system that plays an important role in many homeostatic events in the body. In particular, it takes on a basic task in the regulation of fluid-electrolyte balance, blood volume, and arterial blood pressure and maintaining at the physiological levels (12, 17, 24, 39). Following bleeding, loss of sodium or fluid, systemic blood pressure decreases. This decrease leads to a decrease in intrarenal perfusion pressure. This leads to an increase of renin secretion by juxtaglomerular cells. Major signals leading to juxtaglomerular cells and causing renin secretion are; the reduction of tension of renal afferent arteriole wall (vascular baroreceptor), the decrease in the concentration of $\mathrm{NaCl}$ in macula densa and stimulation of juxtaglomerular adrenergic receptors.

In plasma, renin hydrolyzes angiotensinogen, an ot2 globulin, which is mainly synthesized by the liver, to angiotensin I (a decapeptide). In angiotensin I ACE (angiotensin-converting enzyme) produced by the lungs is converted to angiotensin II (octapeptide). Angiotensin II initiates some biological events by being bound to specific receptors in the target organs. Its main effects are; increase in vascular tone and increase of aldosterone secretion in adrenal zona glomerulosa. Aldosterone results in sodium retention and potassium excretion by increasing the activity of the sodium-potassium pump in the distal tubule cells. Positive sodium balance reduces renin secretion through negative feedback by leading to an increase in plasma volume with fluid retention $(12,13)$.

Circulating angiotensin II also directly inhibits renin secretion. Thus, angiotensin II and aldosterone cooperate to revitalize renal perfusion and increase blood pressure.

Since the repressive effect of angiotensin II is increased by sodium uptake and reduced by sodium loss, the amount of angiotensin II and plasma sodium are in an interaction in the regulation of systemic blood pressure. The RAA system also controls potassium balance. Hyperkalemia stimulates aldosterone secretion and aldosterone increases potassium excretion by activating the renal $\mathrm{Na} / \mathrm{K}$ pump. Aldosterone secretion also decreases with the decrease of potassium level $(13,18)$.

\section{Effect of Physical Exercise on the Renin- Angiotensin-Aldosterone System}

In many studies in the 1950s, a decrease in renal perfusion pressure was mentioned during physical exercise. In studies using renal clearance measurement techniques with para-amino hippuric acid (PAH), a decrease in renal plasma flow was associated with the intensity of the study and it has been shown that a decrease in exercise in the hot environment increases further (21). In the following years, with the development of radioimmunoassays (IUD) system, renal ischemia has been defined as the main stimulant of the mechanisms regulating renin secretion.

Studies on the effect of physical activity in animals and humans have shown significant increases in plasma renin level or activity (14). The magnitude of the renin increase was found to be related to the severity of exercise (28).

Subsequent studies have confirmed these observations, and renal hypoperfusion is now considered to be the physiological mechanism of renin stimulation $(3,50)$ a However, there are other possible factors and other stimuluses to the juxtaglomerular cells for renin secretion. With this in mind, valid hypotheses can be summarized as follows:

1. Exercise causes a significant loss of sodium and water through perspiration if performed in a heavy and hot environment. This leads to the reduction of extracellular fluid and thus renal perfusion decreases. While Physical exercise also causes more blood to be delivered to muscle tissue, 
which requires more oxygen consumption and reduces renal perfusion further. As a result, sodium loss stimulates renin secretion by reducing sodium filtration from glomeruluses and decreasing sodium levels in macula densa.

2. Physical activity increases renal sympathetic tone by activating adrenoreceptors on juxtaglomerular cells. This leads to an increase of renin secretion. Increase of sympathetic tone leads to vasoconstriction of the afferent arteriole, thus causes to renal hypoperfusion and renin secretion. Catecholamines in circulation, mainly norepinephrine, which stimulate adrenoreceptors in vessels and at the level of juxtaglomerular cells increase during physical stress. the activation of the adrenergic system generating with some hemodynamic changes in working muscles, such as increases in peripheral vascular resistance caused by reflexes generated by afferent impulses, are mainly related to response to the isometric exercise (29).

3. The increase of blood flowing from the Splanchnic circulation to the muscles during exercise decreases hepatic blood circulation and reduces the metabolic clearance of renin (44).

In recent studies, after it was shown that angiotensin II is the main regulator of steroid production in adrenal zona glomerulose, the reninangiotensin response was started to be investigated together with aldosterone response. This event helped explain the physiological meaning of the increase in renin.

Costill et al (10) first emphasized the role of aldosterone as the sodium-retaining hormone, which is controlled by angiotensin II and prevents sodium loss bond up with long-term exercise perspiration. Some authors observed that renin and aldosterone levels increased during and after exercise, returned to pre-exercise levels during a rest period of 6-12 hours, and sodium and water excretion remained suppressed for up to 48 hours.

Many investigators have suggested that this observation may explain edema in the lower parts of the leg that is frequently reported after prolonged exercises $(35,58)$. Alterations in the RAA system against various types of exercise have been handled in other studies demonstrating parallel increases in renin, angiotensin II, and aldosterone levels $(8,27)$.

Staessen et al (50) found that plasma levels of angiotensin and aldosterone increased with similar rates of PRA in mild and moderate exercise $(30 \%$ and $60 \%$ ), or that angiotensin II increased significantly more than PRA and aldosterone in maximal (above anaerobic threshold) exercises.

These authors hypothesize that metabolic acidosis due to excessive anaerobic exercise inhibits the breakdown of angiotensin II, or that adrenal glomerulosa may have a delayed response to a sudden increase in angiotensin II. However, There are different judgments between the response of aldosterone to exercise and the response of PRA and angiotensin II. Because it is possible that other mechanisms interfere in aldosterone regulation (13).

Bonelli et al (5) Reported that the administration of propranolol, a beta-adrenergic blocker, in humans may suppress renin release during exercise but does not affect the increase in aldosterone levels. This disclosure brings to mind that an increase in serum potassium level may directly stimulate aldosterone release. Evidence supporting this concept is the increase in intra- and extracellular potassium levels due to physical exercise shown in many studies (13, 57). Similarly, the ACE inhibitor which blocks the formation of angiotensin II had no effect on the aldosterone response to captopril, maximal exercise (53). Furthermore, since potassium level drops during exercise after captopril administration, ACTH may act as an aldosterone stimulant. Recently, it was found that an increase in aldosterone was associated with an increase in ACTH in submaximal exercise and it was interesting that cortisol, mainly regulated by ACTH increased only in maximal exercise (100\% Max VO2). Thus, it is clear that aldosterone secretion during exercise can be regulated by many factors that may be dependent or independent of each other. Whether or not any of these factors is dominant may also depend on the working conditions. Whether endogenous or exogenous, all of these factors potentially affect the response of RAA such in other hormonal responses. Some of these are explained below.

\subsection{Age and Gender}

According to current information, there are no specific findings to demonstrate age-related differences in response to exercise in the RAA system. However, resting levels of renin and aldosterone are known to decrease with age. Maresh et al (33) report that maximal exercise causes a higher increase in plasma renin activity and aldosterone levels in women than in men. 
Kinugawa et al (25) applied to the subjects 15minute submaximal treadmill test in their study on 20 men $(31.9 \pm 1.3$ years $)$ and 15 women $(29.2 \pm 2.5$ years) without voluntary training.

Plasma renin activity during rest and exercise was found to be higher in males than females. In plasma aldosterone level, Although the resting value was higher in men, no difference was found between the two groups during and after exercise. When basal and peak renin-angiotensin-aldosterone system activities of all subjects were examined, a positive correlation was found between pre- and post-exercise measurements.

The response of the renin-angiotensin and aldosterone system to maximal and submaximal exercises in sedentary people is significantly higher. However, it was reported that there was no significant difference in the terms of gender in other parameters except plasma renin activity (25)

\subsection{Menstrual Cycle}

Hormones that balance the body's water sodium levels vary considerably throughout the menstrual cycle. In eumenorrheic athletes, preexercise levels of renin and aldosterone were found to be higher in the mid-luteal phase of the menstrual cycle than in the follicular phase. While the increase in PRA was similar in both of these menstrual phases during submaximal exercise ( $80 \% \mathrm{Max} \mathrm{VO} 2)$, aldosterone response was reported to be greater during the mid-luteal phase than during the follicular phase (51).

High levels of aldosterone after rest and exercise may be due to the high level of progesterone (56). This may lead to a decrease in the sodium-potassium ratio and a reduction in the sodium-potassium loss by sweating. however, in amenorrheic athletes, the resting level of aldosterone is higher than in eumenorrheic athletes, progesterone levels are lower in amenorrheic athletes, and the aldosterone response to exercise is similar to that of eumenorrheic athletes during the follicular phase. In this case, high aldosterone level is seen to be consistent with the overall increase in adrenal cortical activity (11).

\subsection{Posture}

In a study by Wolf et al (60) who examine the effect of posture on the renin-angiotensinaldosterone system in moderate exercise and rest on 5 healthy male subjects, the subjects were rested in a supine position for 15 minutes in water and then in a sitting position outside the pool. The decrease in plasma renin activity between the two conditions was insignificant according to the blood samples taken from the subjects. Aldosterone levels were found to be lower and insignificant in the supine resting position in the water than in the normal sitting position.

Afterward, Cycling ergometer test in the supine position with loading intensity and freestyle swimming in the water were done by subjects (40$50 \%$ Max VO2). Plasma renin activity and aldosterone levels significantly increased according to blood samples taken 15 minutes after exercise. No difference was found between the two exercises in terms of plasma renin activity and aldosterone levels. Moderate and short-term exercises stimulate renin and aldosterone production. It was emphasized that the increase in renin and aldosterone levels were lower in moderate exercise (40-50\% Max VO2) in horizontal position than standing exercise (59).

It has been reported that the inhibitory effects of extraneous effects on renin-angiotensin and aldosterone on the aldosterone system are at a negligible level during exercises such as moderate swimming and staying supine in water (60).

\subsection{Salt Intake}

During the implementation of diets containing normal and high sodium, short-term exercise leads to a marked increase in renin level. However, there was no increase in renin level in long-term exercise in the case of salt loading (3).

Morgan and ark. (38) divided 8 male subjects into two groups and subjected them to a 2-hour exercise (Max VO2) at $38 \pm 0.0 \mathrm{C}$ and in a $60 \pm 1.1 \%$ humid room. During exercise, one group did not take any liquid (dehydration), the other received 20 mmol L sodium chloride solution before and after every 15 minutes of exercise. Blood samples and each amount of perspiration lost were taken just before the exercise and at the 60th and 120th minutes of the exercise. According to the results obtained, plasma aldosterone (Dehydration: $53.8 \pm$ 3.8, Euydration: $40.0 \pm 4.3 \mathrm{ng} / \mathrm{dl}$ ) level was found to be more significant in the dehydration trial than the Euydration trial $(\mathrm{P}<0.05)$.

A large amount of perspiration $(\mathrm{Na})$ and $\mathrm{Cl}$ loss can occur in acute exercise in a warm environment without taking fluid. This is potentially related to 
the amount of $\mathrm{Na}$ in the extracellular fluid, plasma aldosterone secretion and sympathetic nerve activity (38)

\subsection{Thermal Tension}

Following prolonged exposure to heat stress, The reduction in sodium output by sweat glands as an adaptation is a well-known mechanism. At rest, there is also a decrease in sodium secretion as an effect of an increase in aldosterone and renin (16). While the increase in aldosterone is significantly suppressed in parallel with the period of adaptation to the environment, after adaptation to a warm environment, a further reduction in sodium concentration occurs with sweat during exercise. This is interpreted as an increase in the response of eccrine sweat glands to aldosterone (16).

In a study conducted by Armstrong et al (2) on 13 healthy men who were not acclimatized to the heat, subjects exercised for 8 days in a room at $41.2^{\circ} \mathrm{C}$ and rested for 44 minutes. The 1 st, 4 th. On the 8 th days of the study, blood samples were taken from the subjects before and after training and plasma renin, angiotensin and aldosterone values were evaluated. According to this, significant increases in renin, angiotensin and aldosterone values occurred in the measurements on the 1st and 8th days.

\subsection{The Elevation}

Many observations show abnormal RAA response to exercise during hypoxemia (nonhypobaric) or high altitude exposure. While some authors report that renin values are low and high after rest or exercise, the majority of studies show that elevation has a suppressive effect on aldosterone levels in both conditions (36, 49). Furthermore, the difference between renin and aldosterone response during hypoxemic exercise is widely accepted $(6,31,48)$. As a possible explanation of this phenomenon, several different mechanisms have been proposed, such as the reduction in the conversion of angiotensin I to angiotensin II, and the effect of an angiotensin II inhibitor mediating aldosterone secretion, reducing the time of pulmonary passage limiting contact between angiotensin I and membrane-bound ACE. $(9,36)$. Although there is no evidence of aadrenergic inhibitor mechanism, recent studies have shown that ANP and digoxin-like factors are likely aldosterone inhibitors (6). The difference between renin and aldosterone response during height exposure disappears over time. This shows that there is an adaptation mechanism.

Suppression of aldosterone response to increased PRA after rest or exercise may have an important role in preventing pulmonary edema and excessive sodium retention in acute mountain disease during rapid ascent to over-elevation (30). Bocqueraz et al (4) subjected 13 male subjects to 60minute cycling exercise in the four cases, in normoxia and hypoxia ( $\mathrm{PB}=594 \mathrm{hPa}), 55 \%$ and $75 \%$ of maximal aerobic power. Before exercise, Plasma renin and aldosterone levels were measured from blood samples taken at 15, 30, 45 and 60th minutes of exercise. A significant variation in plasma renin and aldosterone levels did not occur in exercise in $55 \%$ of maximal aerobic power in hypoxia and normoxia, whereas a significant increase in plasma renin and aldosterone levels occurred in exercise in $75 \%$ of maximal aerobic power in hypoxia and normoxia.

\subsection{Training}

Although there is no evidence that training affects resting levels of renin and aldosterone, renin and aldosterone levels after exercise showed less increase in trained people than untrained $(19,34)$. This indicates that the fluid transfer from the extravascular space to the intracellular compartment is less during exercise.

Differently, some authors state that the increase in renin and angiotensin II levels is similar between trained and untrained individuals in studies where hormone values are kept close to each other by minimizing differences such as age, gender and body weight. Studies in which the same group of subjects as female basketball players are used show that the increase in renin and aldosterone after maximal exercise is significantly different according to before and after the basketball season (33)

Patlar (42) had seven healthy sedentary men performed exhaustion exercise on an acute cycling ergometer. At the end of the study, before and after exercise, the measured plasma renin, and aldosterone levels 2 and 24 hours after exercise. Plasma renin and aldosterone levels significantly increased immediately after exercise. It was reported that renin and aldosterone levels 2 hours after 
exercise decreased to pre-exercise level and also decreased to below rest level 24 hours after exercise.

Mannix and et al (32) subjected 10 healthy sedentary men to exercise on a bicycle ergometer with a load gradually increased until the fatigue occurs. When the blood samples taken from the subjects were evaluated, it was stated there was a significant increase in plasma renin and aldosterone concentrations during exercise (from Ald $11.2 \pm 2.2$ $18.8 \pm 3.4 \mathrm{ng} / \mathrm{dl}$; Ren $5.1 \pm 1.1$ to $8.2 \pm 1.6 \mathrm{ng} / \mathrm{ml})(\mathrm{P}$ $<0.05)$. And there was a positive correlation between plasma renin and aldosterone concentrations ( $\mathrm{r}=$ 0.80; $\mathrm{P}<0.001)$. Altenkirch et al (1) checked the subjects' renin and aldosterone levels after a testing marathon (42.195m.) applied to 16 well-trained men. Before and after training, blood samples were taken from the subjects after 3 hours and after 31 hours. According to this example, significant increases in renin-aldosterone concentrations occurred before and after training. Hormones that regulate fluid play an important role in providing fluid regulation during and immediately after long-term physical exercises. However, they do not show the same effect in later periods (1).

\subsection{The Type of Exercise}

Intense physical exercise completely disrupts body homeostasis. It causes metabolic and hemodynamic changes not only in skeletal muscles but also in distant organs. In response to acute physical exercise, a reduction in glomerular filtration occurs with stimulation of the reninangiotensin-aldosterone system (45). Patlar (43) reported that acute and 4-week chronic submaximal exercise applied to football players caused significant changes in plasma renin and aldosterone levels. Accordingly, acute and chronic exercise increases plasma renin and aldosterone levels significantly. Two hours of rest and fluid intake after exercise reduces plasma renin and aldosterone levels to pre-exercise level. In the male runners who participated in long-distance running races, aldosterone levels gradually increased $(500 \mathrm{~km}$ race of 18 laps over 20 days), accordingly, sodium excretion decreased with urine and it was reported that aldosterone and sodium excretion levels returned to normal after 70 hours of rest (52). In marathon runners, it was determined that aldosterone secretion increased significantly after completion of the race and returned to normal after 22 hours $(40,47)$.
Increases in PRA and aldosterone after maximal exercise based on swimming were determined lower than those observed after maximal exercise during running (22). This phenomenon is linked to different hemodynamic conditions between running and swimming. As a matter of fact, the fluid change and the water pressure caused by the horizontal position can reduce the PRA response to exercise. While Some other studies have confirmed that PRA and aldosterone levels are lower after immersion, there is no report of changes in renin and aldosterone levels after maximal or submaximal exercise during swimming (52). Ghaemmaghami et al (20), in a study performed on rats doing swimming exercise, found a significant increase in plasma renin activity after training in which maximal VO2 consumption of rats increased by $10 \%$ and plasma osmolality increased by $2 \%$. After the training, While a $10 \%$ decrease in body weight of rats and a $6 \%$ in blood pressure occurs, a $10 \%$ significant decrease in plasma osmolality and a $4 \%$ in $\mathrm{Na}$ concentrations occur. According to these results, it can not be said that swimming exercises lower blood pressure. In another study, Warburton et al (54) randomly divided 20 sedentary (30 years \pm 4 ) men into 3 groups (Control group, continuous running group, interval training group). The exercise group subjects followed their unique training program for 12 weeks. In the measurements after exercise, significant variations were provided in Max VO2, throb volume and blood pressures of the exercise groups. While, in angiotensin II concentration, A significant improvement was being obtained in both groups 1 week after the start of exercise, but this value returned to its normal level in the following weeks. In addition, no significant difference was found between the groups that were subjected to different training programs in terms of hormones providing fluid regulation.

\section{CONCLUSION}

Studies over the last 20 years have tried to explain the role of the RAA system in the physiological response to physical exercise.

In this review, an analysis of experimental and clinical studies on this subject has been made. Physical exercise leads to a number of changes in the plasma levels of renin, angiotensin and aldosterone, which represent the adaptation of the human body to a new biological environment. In particular, significant increases in plasma renin, angiotensin and aldosterone levels occur in submaximal and 
maximal exercise intensity. Hormone levels return to normal with the end of the exercise. Factors such as age and gender, menstrual cycle, salt intake, posture, thermal tension, elevation, training, type of exercise have a major impact on the response of RAA system to exercise. A relationship between physical activity and enduring endocrine changes could not be demonstrated.

In addition, many studies are needed to demonstrate the behavior of the hormonal system both during exercise and during the normalization process after different conditions. New hormone regulation mechanisms such as susceptibility to aldosterone and angiotensin II and changes in receptor number should also be investigated.

\section{REFERENCES}

1. Altenkirch HU, Gerzer R, Kirsch KA, Weil J, Heyduck B, Schultes I and Röcker L (1990) Effect of prolonged physical exercise on fluid regulating hormones, Europen Journal Appl Physiol, 61,3-4, 209-213.

2. Armstrong LE, Francesconi RP, Kraemer WJ, Leva N, De Luca JP and Hubbard RW (1989) Plasma cortisol, renin and aldosterone during an intense heat acclimation program. Int J Sports Med, 10(1): 38-42.

3. Aurell M, Vikgren P (1971) Plasma Renin Activity in Su $\neg$ pine Muscolar Exercise, J App Physiol, 31:839-41.

4. Bocqueraz O, Koulmann N, Guigas B, Jimenez C and Melın B (2004) Fluid-Regulatory Hormone Responses during Cycling Exercise in Acute Hypobaric Hpoxia ,Medicine, Science in Sports, Exercise, 36, 10, 1730-1736.

5. Bonelli J, Waldhausl W, Magometschnigg D, Schwarzmeier J, Korn A and Hitzenberger G (1977) Ef $\neg$ fect of Exercise and Prolonged Oral Administra $\neg$ tion of Propranolol on Haemodynamic Variables, Plasma Renin Concentration, Plasma Aldoster $\neg$ one and c-AMP, Eur J Clin Invest, 7:337-43.

6. Bouissou P, Guezennec CY, Galen FX, Defer G, Fiet J and Pesquies PC (1988) Dissociated Response of Alᄀdosterone From Plasma Renin Activity During Prolonged Exercise Under Hipoxia, Horm Melabul Res, 20:517-21.

7. Bouissou P, Richalet JP, Galen FX, at al (1989) Effect of (-) Adrenoceptor Blockade on Renin Aldosterone And Alpha-ANF During Exercise At Alti-tude. J Appl Physiol, 67, 141-6.

8. Buono MJ, Yeager JE (1991) Increases in Aldosterone Precede Those of Cortisol During Graded Exerncise, J Sports Med Phys Fitness, 31, 48-51.

9. Colice GL, Ramirez G (1985) Effect of Hypoxemia on the Renin Angiotensin Aldosterone System in Hu $\neg$ mans, J Appl Physiol, 58, 724-30.

10. Costill DL, Branam G, Fink W and Nelson R (1976) Exerาcise Induced Sodium Conservation: Changes in Plasma Renin and Aldosterone, Med Sci Sports, 8-209-13.

11. De Souza MJ, Maresh CM, Maguire MS, Kraemer WJ, Flora GG and Goetz KL (1989) Menstrual Startus and Plasma Vasopressin. Renin Activity, and Aldosterone Exercise Responses, J Appl Physiol, 67, 736-43.

12. Ekmekçi A, Canberk A ve Berkman K (2000) ReninAngiotensin Sistemi,Angiotensinler,Angiotensin Reseptörleri ve Angiotensin Antogonistleri, Park Matbaacılık, İstanbul.
13. Fallo F (1993) Renin-angiotensin-aldosterone system and physical exercise.J Sports Med Phys Fitness, 33, 306-12.

14. Fasola AF, Martz BL and Helmer OM (1966) Renin Activity During Supine Exercise in Normotensives and Hypertensives. J Appl Physiol, 21,1709-12.

15. Fitzsimons JT (1998) Angiotensin, Thirst and Sodium Appetite. Physiological Reviews, 78, 3, 583-686.

16. Francesconi RP, Sawka MN and Pandolf KB (1983) Hvpohydration and Heat Acclimation Plasma Renin and Aldosterone During Exercise, J Appl Phys -iol, 55, 1790-4.

17. Freeman RH, Davis JO (1983) Factors Controlling Renin Secretion and Metabolism, In: Genest J, Kuchel P, Hamet P, Cantin M eds, Hypertension, New York, McGraw-Hill, 2-550.

18. Ganong WF(1996) Tıbbi Fizyoloji, Cilt 1, 17. Baskı, (Çev: Türk Fizyolojik Bilimler Derneği), Barış kitabevi, Ankara.

19. Geyssant A, Geelen G, Denis Ch, at al (1981) Plasma Vasopressin, Renin Activity and Aldosterone Effect of Exercise and Training, Eur .1 Appl Physרiol Occup Physiol, 46, 21-30.

20. Ghaemmaghami F, Allevard AM, Fareh J, Geelen G and Gharib C (1991) Effects of exercise and prolonged exercise training on blood pressure, vasopressin and plasma rennin activity in spontaneously hypertensive rats. Eur J Appl Phys 7 iol Occup Physiol, 62, 3, 198-203.

21. Grimby G (1965) Renal Clearances During Prolonged Supine Exercise at Different Loads, J Appl Physiol, 20, 1294-8.

22. Guezennec CY, Defer G, Gazorla G, Sabathier C and Lhoste F (1986) Plasma Renin Activity, Aldosterone and Catecholamines Levels When Swimming and Running, Eur J App] Physiol, 54, 632-7.

23. Guyton MD, Hall JE (1996) Textbook of Medical Physiologh, Tıbbi Fizyoloji, (Çev: Çavuşoğlu H), 9. Baskı,Yüce Yayınları, Alemdar Ofset, İstanbul.

24. Hackental E, Paul M, Ganten D at al (1990) Morphology, Physiology and Molecular Biology of Renin Secretion. Physiol Rev, 70:1067-116.

25. Kinugawa T, Ogino K, Miyakoda H, Saitoh M, Hisatome I, Fujımoto Y, Yoshida A, Shigemasa C and Sato R (1997) Responses of Catecholamines, Renin-Angiotensin System, and Atrial Natriuretic Peptide to Exercise in Untrained Men and Women. Gen. Pharmac, 28, 2, 225-228.

26. Kirby CK, Convertino VA (1986) Plasma Aldosterone and Sweal Sodium Concentrations After Exercise and Heat Acclimation, J Appl Physiol, 61, 967-70.

27. Kosunen KJ, Pakarinen AJ (1976) Plasma Renin, Angiotensin II, and Plasma and Urinarv Aldosterone in Running Exercise, J Appl Phvsiol, 41, 26-9.

28. Kotchen TA, Hartley LH. Rice TW, Mougey EH, Jones LG and Mason JW (1971) Renin, Norepinephrine, and Epinephrine Responses to Graded Exercise, J Appl Physiol, 31, 178-84.

29. Kozlowski S, Brzezinska Z, Nazar K, Kowalski W and Franczyk M (1973) Plasma Catecholamines During Sustained İsometric Exercise, Clin Sci Mol Med, 15, 723-31.

30. Lawrence DL, Shenker V (1991) Effect of Hypoxic Exercise on Atrial Natriuretic Factor and Aldosterone Regulation, Amer J Hyperl, 4, 341-7.

31. Maher JT, Jones LG, Hartley H, Williams GH and Rose LI (1975) Aldosterone Dynamics During Graded Exercise at Sea Level and High Altitude, J Appl Physiol, 39, 18-22.

32. Mannix ET, Plange P, Aronof GR, Manfredi F and Farber MO (1990) Atrial natriuretic peptide and the reninaldosteron axis during exercise in man. Med Sci Sports Exerc, 22, 6, 785-9. 
33. Maresh CM, Wang BC. Goetz KL (1985) Plasma Vasopressin, Renin Activity, and Aldosterone Responses to Maximal Exercise in Active College Females, Eur J Appl Physiol, 54:398-403.

34. Melin B, Eclache JP, Geelen G, at al (1980) Plasma AVP, Neurophysin, Renin Activity and Aldosterone During Submaximal Exercise Performed Until Exhaustion in Trained and Untrained Man, Eur J Appl Physiol, 44,141-51.

35. Milledge JS, Bryson EI, Catlev DM at al (1982) Sodium Balance, Fluid hHomeostasis and TheRenin Aldosterone System During The Prolonged Exercise of Hill Walking, Cli Sci, 62, 595-604.

36. Milledge JS, Catley DM (1982) Renin, Aldosterone and Convening Enzyme During Exercise and Acute Hypoxia in Humans, J Appl Physiol, 52, 320-3.

37. Milledge JS, Catley DM, Ward MP, Wiliams ES and Clarke CRA (1983) Renin Aldosterone and Angiotensin Converting Enzyme During Prolonged Altitude Exposure, J Appl Physiol, 55, 699-702.

38. Morgan RM, Patterson MJ and Nimmo A (2004) Acute effects of dehydration on sweat composition in men during prolonged exercise in the heat. The American College of Sports Medicine, 182, 37.

39. Muller J (1988) Regulation of Aldosterone Biosynthe $า$ sis. Heidelberg: Springer-Yerlag Berlin.

40. Newmark StR, Himathongkam T, Martin RP, Cooper KH and Rose LI (1976) Adrenocortical Response to Marathon Running, J Clin Endocrinel Metab, 42, 393-8.

41. Noyan A (2000) Yaşamda ve Hekimlikte Fizyoloji, 10. Baskı, Meteksan An. Şir, Ankara.

42. Patlar S (2009) Effect of Acute Submaximal Exercise on Plasma Renin and Aldosterone Levels in Sedentary People, Asian Journal of Chemistry, 21, 9, 6957-6961.

43. Patlar S (2011) Effect of acute and chronic submaximal exercise on plasma renin and aldosterone levels in football players, Isokinetics and Exercise Science, vol. 19, no. 3, pp. 227-230.

44. Pedersen EB, Danielsen H, Nielsen AH, at alI (1986) Effect of Exercise on Plasma Concentrations of Arginine Vasopressin, Angiotensin II and Aldosterone in Hypertensive and Normotensive Renal Transplant Recipients, Scand J Clin Lab Invest, 46, 151-7.

45. Podhorska OM, Dziegel P, Gomulkiewez A, Dolinska KB, Murawska CE, Jethon Z and Zabel M (2004) The role of AT1 and AT2 angiotensin receptors in the mechanism of apoptosis in renal tubular cells after physical exercise, Rocz Akad Med Bialymst, 49, 1, 8-10.

46. Pouramir M, Haghshenas O and Sorkhi H (2004) Effects of Gymnastic Exercise on the Body Iron Status and Hematologic Profile. Iran J. Med. Sci, 29, 3, 140-141.

47. Rocker L, Kirsch KA, Hey duck B and Altenkirch U (1989) Influence of Prolonged Physical Exercise on Plasma Volume,
Plasma Proteins, Electrolytes and Fluid Regulating Hormones, Inl J Sports Med, 10, 270-4.

48. Shigeoka JW, Colice GL and Ramirez G (1985) Effect of Normoxemic and Hypoxemic Exercise on Renin and Aldosterone. J Appl Physiol, 59, 142-8.

49. Slater JDH, Tuffley RE, Williams ES at al (1969) Cunirol of Aldosterane Secretion During Acclimati-zation to Hypoxia in Man, Cli Sci, 37, 327-41.

50. Staessen J, Fagard R, Hespel P, Lijnen P, Vanhees L and Amery A (1987) Plasma Renin System During Exercise in Normal Man, J Appl Phxsiol, 63, 188-94.

51. Stachenfeld NS, Dipietro L, Kokoszka CA, Silva C, Kefe DL and Nadel ER (1999) Physiological variability of fluidrugulation hormones in young women. J Appl Physiol, 86, 1092-1096.

52. Wade CE, Hill LC, Hunt MM and Dressendorfer RH (1985) Plasma Aldosterone and Renal Function in Run`ners During A 20-day Road Race, J Appl Physiol, 54, 456-60.

53. Wade CE, Ramee SR. Hunt MM and While CJ (1987) Hor $\neg$ monal and Renal Responses to Converting En $\neg$ zyme Inhibition During Maximal Exercise. J Appl Physiol, 63, 1796-800.

54. Warburton DE, Haykowsky MJ, Quinney HA, Blackmore D, Teo KK, Taylor DA, McGavock J and Humen DP (2004) Blood volume expansion and cardiorespiratory function: effects of training modality. Med Sci Sports Exercise, 36, 6, 991-1000.

55. Weiss M, Pollert R, Stehele R and Weicker H (1988) Differาences in Sympathoadrenal, Hormonal, and Meta $\neg$ bolic Adaptation to Submaximal and Maximalarm and Leg Work Compared with Whole Stroke in Breast-Style Swimming, Int .1 Sports Med, 9, 118-24.

56. Wells CL, Horvath SM (1973) Heat Stress Responses Trebled to The Menstrual Cycle, J Appl Physiol, 35, 1-5.

57. Wilkerson JE, Horvath SM, Gulin B, Molnar S and Diaz FJ (1982) Plasma Electrolyte Content and Concen ᄀtration During Treadmill Exercise in Humans. J Appl Physiol, 53, 1529-39.

58. Williams ES, Ward MP, Milledge JS, Withey WR, Older MWJ and Forsling ML (1979) Effect of The Exาercise of Seven Consecutive Days Hill-Walking on Fluid Homeostasis, Cli Sci, 56, 305-16.

59. Wolff JP, Nguyen NU, Dumoulin G and Berthelay S (1986) Plasma Renin and Aldosterone Changes During Twenty Minutes Moderate Exercise, Eur J. Appl Physiol, 54, 602-7.

60. Wolff JP, Nguyen NU, Dumoulin G and Berthelay S (1987) Relative effects of the supine posture and of immersion on the renin aldosterone system at rest and during exercise .Eur J Appl Physiol, 56,3,345-349.

61. Yilmaz B (1999) Hormonlar ve Üreme Fizyolojisi, Feryal Matbaa, 1.Basım, 247-371, Ankara. 